ARTICLE

DOI: $10.1057 /$ s41599-018-0144-2

\title{
An introduction to achieving policy impact for early career researchers
}

\author{
Megan C Evans ${ }^{1,2} \&$ Christopher Cvitanovic ${ }^{3}$
}

\begin{abstract}
Scientists are increasingly required to demonstrate the real world tangible impacts arising from their research. Despite significant advances in scholarship dedicated to understanding and improving the relationships between science, policy and practice, much of the existing literature remains high level, theoretical, and not immediately accessible to early career researchers (ECRs) who work outside of the policy sciences. In this paper, we draw on the literature and our own experiences working in the environmental sciences to provide an accessible resource for ECRs seeking to achieve policy impact in their chosen field. First, we describe key concepts in public policy to provide sufficient background for the non-expert. Next, we articulate a number of practical steps and tools that can help ECRs to identify and enhance the policy relevance of their research, better understand the policy world in practice and identify a range of pathways to achieving impact. Finally, we draw on our personal experiences to highlight some of the key individual characteristics and values that are needed to operate more effectively at the interface of science, policy and practice. Our hope is that the information and tools provided here can help to empower ECRs to create their own pathways to impact that best suit their individual goals, circumstances, interests and strengths.
\end{abstract}

\footnotetext{
${ }^{1}$ Centre for Biodiversity and Conservation Science, School of Earth and Environmental Sciences, University of Queensland, Brisbane, QLD, Australia. ${ }^{2}$ Centre for Policy Futures, University of Queensland, Brisbane, QLD, Australia. ${ }^{3}$ Centre for Marine Socioecology, University of Tasmania, Hobart, TAS, Australia. Correspondence and requests for materials should be addressed to M.C.E. (email: megan.evans@uq.edu.au)
} 


\section{Introduction}

cientific knowledge, alongside other knowledge systems (Cash et al., 2003; Cornell et al., 2013; van Kerkhoff and Lebel, 2006), has a critical role to play in helping humanity navigate modern challenges such as those associated with climate change, biodiversity loss, water scarcity and food security (Malhi et al., 2008; Mekonnen and Hoekstra, 2016; Nash et al., 2017; Pecl et al., 2017; Tai et al., 2014). The accumulation of scientific evidence alone, however, will not suffice. Rather, our ability to successfully navigate contemporary issues and steer society towards a positive future is dependent on the ways in which scientific knowledge is applied in policy and practice (Cairney, 2016; Caplan, 1979; Evans et al., 2017; Shonkoff, 2000; Sutherland et al., 2004; Weiss, 1979). As a result scientists have come under greater societal and political pressure to more actively engage with decision-makers to facilitate knowledge exchange and the uptake of scientific knowledge into decision-making processes (Boswell and Smith, 2017; Lubchenco, 1998; Sivertsen, 2017; Stein, 2018). At the same time scientists are increasingly required to demonstrate the tangible and real-world impacts ${ }^{1}$ arising from their research (Boswell and Smith, 2017; Sivertsen, 2017; Smith and Stewart, 2017; Stein, 2018).

An emergent body of literature has sought to understand and enhance the relationship between science, policy and practice (Cvitanovic, Hobday, van Kerkhoff, Wilson, et al., 2015; Fazey et al., 2013), and identify the core principles and processes that are required for impact (Cairney et al., 2016; Cairney and Kwiatkowski, 2017; Cairney and Oliver, 2017; Cvitanovic et al., 2016; Marshall et al., 2017; Reed et al., 2014). Despite this academic progress, however, the practicalities of how to successfully influence policy processes that are laden with diverse ideas, values and norms can remain elusive to many scientists. This is particularly pertinent among early career researchers (ECRs), with evidence showing that while achieving policy impact is an important personal goal for many ECRs (including postgraduate students), they are not always skilled or trained in how to engage with decision-makers, nor understand the complexities of policy processes (e.g., Bernstein et al., 2017; Cvitanovic, Hobday, van Kerkhoff and Marshall, 2015; Marcella et al., 2017). Further, ECRs must not only navigate trade-offs inherent in balancing science-policy work with their research (Sarkki et al., 2014), but to do so in a highly insecure career stage characterised by short-term contracts and extreme mobility (Kellard and Śliwa 2016; Phillips and Heywood-Roos, 2015).

Here we draw on the literature and our own experiences working in the environmental sciences to provide an accessible resource for ECRs seeking to achieve tangible impacts in their chosen field. First, we describe key concepts in public policy to provide sufficient background for the non-expert. Next, we articulate a number of practical steps and practical tools that can help ECRs to identify the policy relevance of their research, better understand the policy world in practice, build diverse networks, and identify a range of pathways to impact. Finally, we draw on our personal experiences to highlight some of the key individual characteristics and values that ECRs (or even the most senior scientists) need to operate more effectively at the interface of science, policy and practice.

We were inspired to write this perspective from our own experiences as ECRs trying to have a positive impact on policy and practice, whilst operating within the institutional constraints of the university sector which still largely incentivises the 'traditional' academic model of publish or perish (Keeler et al., 2017; Tyler, 2017; Wittemyer et al., 2018). We were also emboldened by the positive feedback we received from ECRs who attended a recent forum that aimed to help Australian environmental scientists understand the practical ways in which they can, at an individual level, influence policy and practice ${ }^{2}$. From these experiences, it became clear to us that many ECRs are lacking the practical steps and tools that can assist them in understanding policy processes and identifying pathways to impact.

In writing this manuscript we acknowledge that a comprehensive body of public policy literature already exists, providing essential background to understanding policy processes (Cairney and Kwiatkowski, 2017; Weible et al., 2012). This literature, however, often assumes a degree of prior theoretical knowledge that ECRs working outside of the policy sciences may not possess. Similarly, other more practical contributions in this field have a tendency to assume the reader already has access to, and knowledge of, relevant policy networks to "build relationships" with (Brisbois et al., 2018; Cairney et al., 2016; Gibbons et al., 2008); and/or is at a career stage where 'service' activities are explicitly stipulated in academic job descriptions (Arlettaz et al., 2010; Wittemyer et al., 2018),

ECRs require support and information tailored to their career stage to enable them to successfully navigate policy processes. For example, evidence from the 2014 UK Research Excellence Framework suggest that ECRs are under-represented in the successful impact case studies, and indeed risk being disadvantaged by formal impact frameworks due the limited job security, networks, and institutional support of ECRs relative to established academics (Laundon, 2017; Marcella et al., 2017; Smith and Stewart, 2017). Further, the models of "impact" visible to ECRs within academia are often exceptional individuals who are advanced in their careers, who may implicitly (or even explicitly) suggest to ECRs that one can only have a positive influence on policy and practice, and maintain a research career, by following the same model.

We acknowledge that while many ECRs are motivated by a desire to achieve impacts on policy and practice, this is not universally the case (Marcella et al., 2017). Indeed, some scholars may feel pressured to 'game' institutionalised impact frameworks (Murphy, 2017; Sivertsen, 2017; Smith and Stewart, 2017), or that current definitions and metrics of "impact" may not necessarily reflect the full scope of benefits derived from research (Stein, 2018). An in-depth exploration of these issues is outside of the scope of this article, but can be found elsewhere (Boswell and Smith, 2017; Marcella et al., 2017; Sivertsen, 2017; Smith and Stewart, 2017; Stein, 2018)

Our intention for this manuscript is to offer practical guidance specifically for ECRs who are interested in engaging with policy and practice to achieve "impact". Existing literature has provided advice for ECRs on communication (Christian, 2018; Kuehne et al., 2014), stakeholder engagement (Duchelle et al., 2009), and diverse opportunities to engage with policy both inside and outside of academia (Bednarek et al., 2018; Petes and Meyer, 2018; Pietri et al., 2013). However, these contributions rarely make explicit links to public policy theory and scholarship, which we seek to do here. Thus, our hope is that the combination of information and tools provided here can help to empower ECRs to create their own pathways to impact that best suit their individual circumstances, interests and strengths.

\section{What is 'policy'?}

Reference to 'science-policy interfaces' has become commonplace in academia (Gluckman, 2016; Pielke Jr, 2007; Sarkki et al., 2014; van den Hove, 2007), and there is a tendency to use the term 'policy' as a catch-all phrase for a range of formal and informal decision-making processes. Thus, in writing this manuscript it is first instructive to define policy and associated key terms, namely politics and management, to help ECRs understand the nuances 
between them, and where they are most likely to achieve impact. For further information and context, we point the reader to key texts (Cairney, 2012; Dovers and Hussey, 2013; Howlett et al., 2009), papers (Boswell and Smith, 2017; Cairney and Kwiatkowski, 2017; Weible et al., 2012) and online resources (e.g., https://paulcairney.wordpress.com/)

Policy, politics and management. A policy can generally be thought of as a statement of intent made by a government body, often with the involvement of non-government individuals and organisations (collectively referred to as policy actors), that describes a problem and broadly outlines how the problem will be addressed (Dovers and Hussey, 2013; Howlett et al., 2009). There is no single agreed definition amongst policy scholars of what policy is and is not (Cairney, 2011; Hogwood and Gunn, 1984). For example, the term 'policy' may refer to a proposal, outcome, formal or informal decision, bundle of legislation, or positions implicitly taken by government due to the absence of public dialogue or action on a problem. For the purposes of this paper, we assume that readers are primarily interested in the 'on-ground' outcomes and positive impacts (as per Reed et al., 2018) that result from the implementation of a policy, rather than symbolic policies which may not be (or ever intended to be) implemented by decision makers. Public policy refers to both the 'sum total' of activity related to policymaking, as well as the interdisciplinary study of the phenomenon (Dovers and Hussey, 2013).

In contrast, the term 'politics' is often used in public discussions to refer to partisan political debate, more generally it encompasses the "bounded conflict" (Lee, 1993) between diverse societal ideas, values, norms, and policy actors. According to Davis (1993):

"Politics is the essential ingredient for producing workable policies, which are more publicly accountable and politically justifiable [...]. We are unable to combine values, interests and resources in ways that are not political" (emphasis in original)

So while policy is distinct from politics, the latter very much influences the former, hence "... all policy is political, and so it should be" (Dovers and Hussey 2013). These systems are imperfect, but we suggest it is pragmatic to learn strategies to engage with policy processes as they currently exist, rather than to wait for an ideal which may never eventuate (Cairney, 2016; Cairney and Kwiatkowski, 2017).

Finally, management refers to the 'on-ground' actions required to implement the policy and achieve the policy goals. For example, a research project which aims to determine the most appropriate type and configuration of actions to implement for the protection of threatened species is primarily a management problem, since the overarching policy goal, style and choice of instrument (i.e. public expenditure) is taken as a given. However, should the researchers also analyse whether the stated policy goal is appropriate, feasible or in line with societal expectations, or suggest that the use of economic incentives or formal regulation may be a more effective policy instrument, then these are primarily questions of policy. Through this example, one can see how the relationship between politics, policy and management is not one-way. The outcomes (or lack thereof) of policy implementation can influence policy discussions in the future, and ideally, a process of policy learning, adaptation and improvement occurs (Dunlop and Radaelli, 2018).

"The" policy process. The next key concept in public policy we will discuss here is the policy cycle or policy process. Numerous models of the policy process exist, and vary marginally with respect to the number, order and names of the stages of the process (Bridgman and Davis, 2000; Cairney, 2011; Dovers and Hussey, 2013; Howlett et al., 2009; Lasswell, 1971). Critics of the model argue that policymaking is rarely as simple and linear as the model implies (Bridgman and Davis, 2003; Everett, 2003), or even that there is no order, coherence or process at all (Cairney, 2011; Cohen et al., 1972; Kingdon, 1984). Of course, "all models are wrong, but some can be useful” (Box, 1976) for understanding and analysing the messy, real-world complexities of phenomena such as policymaking (Dovers and Hussey, 2013).

Notwithstanding the multiple theories and models available in the public policy literature, "the" policy process is frequently referred to in discussions about science policy interfaces and policy impact, hence it is worthwhile to draw out some general guidance. Based on a synthesis of major public policy theories, Cairney and Heikkila (2014) emphasise six key elements of the policy process (Table 1) which are important to consider when identifying pathways to impact; policy actors, networks, institutions, ideas, events and socioeconomic contexts.

Although policymaking in practice may not follow a logical order or strict sequence, it is still helpful to consider different "stages" in recognition of how the six elements may influence policymaking over time (Table 2), since different points in time may present different "windows of opportunity" for influence (Kingdon, 1984; Rose et al., 2017). As emphasised by Dovers and Hussey (2013), it is useful to think of models such as Table 2 as a framework or checklist for describing and analysing policy, rather than as a representation of reality.

The number and diversity of policy actors involved in the process usually varies at different stages (Table 2, Howlett et al., 2009). A larger number of policy actors generally participate in setting the policy agenda and framing the overall policy problem through broader community debate. Specific policy principles and goals are formulated by a smaller network of actors with particular interest in or expertise in a policy problem, and may participate in formal and informal consultation processes. Key policy decisions and the selection of policy instruments are ultimately made by a small number of government decision makers, but the implementation, monitoring and evaluation phases incorporate an increasing number of policy actors with diverse interests and motivations.

A single model or theory of the policy process is not possible, or even desirable, since policymaking varies so drastically across different socioeconomic and political contexts. Similarly, there is no single science-policy interface, but rather a series of spaces in which science may interact with diverse ideas, values, norms, and policy actors (Evans et al., 2017; Head, 2008; Newman et al., 2016; Toomey et al., 2016). Unfortunately, it can be difficult to see how these concepts connect to reality without a practical understanding of how policy works in a particular context. How then can ECRs learn to understand, and ultimately influence policy in practice?

\section{Understanding and influencing policy in practice}

"Laws, like sausages, cease to inspire respect in proportion as we know how they are made" - John Godfrey Saxe (1869)

Policymaking is frequently likened to making a sausage, as "it's ugly and grimy and you'll like it better if you don't watch too closely" (Klein, 2009). While this inelegant description may inspire some to stay within the safe confines of science, we contend that it can be extremely valuable for ECRs interested in having real-world impact to understand how policy operates in practice. Influencing policy processes requires a combination of knowledge, relationships, persistence, and luck (Weible et al., 
Table 1 General elements of the policy process to consider when identifying pathways to policy impact. Adapted from Cairney and Heikkila (2014)

\begin{tabular}{|c|c|c|}
\hline Element & Description & Examples \\
\hline Policy actors & $\begin{array}{l}\text { Organisations and individuals with an interest or concern } \\
\text { with a policy process, and who directly or indirectly interact } \\
\text { with policy processes. Synonymous with "stakeholder". The } \\
\text { "players of the game" (North, 1991). }\end{array}$ & $\begin{array}{l}\text { Government bodies (local, regional, state, federal, national), } \\
\text { peak industry bodies, community groups, non-government } \\
\text { organisation, private companies, professional societies. } \\
\text { Individual policymakers, senior and junior civil servants, } \\
\text { lobbyists, members of the public, Members of Parliament, } \\
\text { Members of Congress, key experts }\end{array}$ \\
\hline Networks & $\begin{array}{l}\text { Relationships between policymakers and other policy actors, } \\
\text { built on trust and mutual interest, which may enable greater } \\
\text { influence on policy processes in exchange for information. } \\
\text { Also referred to as "subsystems" }\end{array}$ & $\begin{array}{l}\text { Usually informal, but may be facilitated by membership of } \\
\text { professional associations, councils, peak bodies or personal } \\
\text { networks. }\end{array}$ \\
\hline Institutions & $\begin{array}{l}\text { Formal and informal rules, norms, practices, and traditions } \\
\text { that influence individual and collective behaviour. The "rules } \\
\text { of the game" (as per North, 1991). }\end{array}$ & $\begin{array}{l}\text { Constitutions, Westminster system of governance, the } \\
\text { judiciary, legislations, property rights, codes of conduct, } \\
\text { cultural norms and traditions, formal meetings of } \\
\text { governments, stakeholder consultation processes. }\end{array}$ \\
\hline Ideas & $\begin{array}{l}\text { Beliefs, dominant forms of knowledge, paradigms and } \\
\text { worldviews held by individuals and organisations or within } \\
\text { networks and political systems that inform how policy } \\
\text { problems are framed, and possible solutions. }\end{array}$ & $\begin{array}{l}\text { Neoliberalism, social democracy, the market, universal } \\
\text { healthcare, globalisation, protectionism, equity and inclusion, } \\
\text { social (in)equality. }\end{array}$ \\
\hline Events & $\begin{array}{l}\text { Routine, infrequent or unexpected events which may create } \\
\text { small or large changes to the policy context, and can open or } \\
\text { close "windows of opportunity" for policy change. }\end{array}$ & $\begin{array}{l}\text { Elections, natural disasters, economic crisis, political crisis, } \\
\text { shift in societal attitudes or opinion, change in Minister } \\
\text { responsible for policy portfolio, change in head of a } \\
\text { government department or body. }\end{array}$ \\
\hline $\begin{array}{l}\text { Socioeconomic } \\
\text { context }\end{array}$ & Economic, social, demographic conditions. & $\begin{array}{l}\text { Unemployment rate, inflation, per capita income, income (in) } \\
\text { equality, birth and death rate, immigration, emigration, key } \\
\text { industries and sectors, natural resources. }\end{array}$ \\
\hline
\end{tabular}

Table 2 Stages in the policy process, as adapted from Howlett et al. (2009) and Dovers and Hussey (2013)

\begin{tabular}{lll} 
Policy actors & Stage & Description \\
\hline Problem framing & $\begin{array}{l}\text { Knowledge gathered, issues debated, policy } \\
\text { problem constructed and framed }\end{array}$ \\
Policy formulation & $\begin{array}{l}\text { Policy options are developed } \\
\text { Decision making }\end{array}$ \\
Implementation & $\begin{array}{l}\text { Policy instrument(s) selected, resources allocated } \\
\text { Monitoring and evaluation }\end{array}$ & $\begin{array}{l}\text { Short and long term results monitored, problems } \\
\text { identified, learning and adaptation }\end{array}$
\end{tabular}

2012). Before going any further, it is worth expanding on these last two points.

First, it cannot be guaranteed that efforts by scientists (or any other policy actor) to impact on policy will be successful. Most policy problems involve complex, dynamic and interconnected social, economic and environmental processes, which are highly uncertain and beyond our direct control. Scientific evidence, even when it is accessible, robust, and compelling, will not always influence policy as much as some would like. This does not mean that policymakers are "complacent" or deliberately ignore science (Sutherland and Wordley, 2017) but rather that science is necessarily only one input into policy processes; which must consider multiple forms of evidence and knowledge, such as traditional and local knowledge (Cash et al., 2003; Evans et al., 2017; Head, 2008; Sturgis and Allum, 2004; van Kerkhoff and Lebel, 2006).
Second, most impacts (even those achieved by experienced academics) take time, commitment, a lot of 'invisible' work, and usually have been achieved in the face of multiple challenges, mishaps and failures. Impacts may be small, some may be large, and most are more likely to emerge gradually over time rather than to appear overnight. Achieving policy impact is hard, and so personal qualities such as resilience and humility are crucial (see 'Personal attributes for achieving impact).

It is also important for ECRs to identify their motives for wanting to engage with policy, and identify and articulate the impacts that they hope to achieve (Reed, 2016, 2017). These could take many forms. For example, they could include personal impacts (e.g., I want to develop a relationship with stakeholder ' $x$ ') through to demonstrable impacts on policy and practice (e.g., I want the government to rezone its existing protected area estate to encompass ' $y$ ' new habitat). They can also span different 
timescales, for example, some might be achievable in one week whereas others might take three (or thirty) years to achieve. It can be helpful to conceptualise impact goals so that they are SMART (Specific, Measurable, Achievable, Relevant and Time-bound); (Rubin, 2002). Ensuring impact goals are clearly articulated, SMART, and reflect individual values and aspirations will increase the likelihood these goals will be achieved (Reed, 2017).

In this section, we outline some practical steps and tools that ECRs can use to (i) enhance their understanding and appreciation of the policy world in practice, (ii) build diverse networks, and (iii) identify pathways to impact. Building the knowledge and relationships required to understand and influence policy processes (Weible et al., 2012) is a long-term, iterative venture. We stress that there is no single approach or order to achieving policy 'impact', but rather diverse approaches which researchers can apply and adapt depending on their research philosophy, career stage, and capacity. Thus, in writing this, our goal is not to provide a comprehensive list of possible pathways to achieving impact, but rather, outline some of the key practical steps that ECRs can use as a starting point to generating impact.

Identify who is involved with policy processes, and why. The first step to having an influence on policy and practice is understanding who is involved in the policy process (Table 2), and why. Identifying these individuals at an early career stage can be particularly challenging given that policy processes involve multiple actors (or stakeholders) with diverse motivations, values and interests. To this end, a range of stakeholder analysis methods can be used to scope out who are the relevant actors (Reed et al., 2009), but it can also be done more simply by asking yourself four key questions:

1. Who might be interested in, benefit from, or be impacted by my research?

2. Why would my research be of interest to these actors?

3. What aspects of my research are most relevant to these actors (which parts of my research align with their goals)?

4. How do each of these actors interact with others (what degree of influence do they hold)?

It is unlikely that you will be able to fully answer these questions straight away. Understanding the deeper nuances of policy processes (e.g., power dynamics, informal rules and norms, and the membership and influence of particular networks) requires access to networks and knowledge that takes time to develop (Cairney and Kwiatkowski, 2017; Oliver and Pearce, 2017; Weible et al., 2012). However, it is possible to begin identifying the more visible elements of the policy process (e.g., which level(s) of government are responsible for a policy problem, what are the relevant formal institutions, and what are the dominant societal worldviews or beliefs shaping policy debate) through observation of relevant public discourse and debate.

Although it may sound obvious, keeping track of topics of interest in the international, national and/or local media is a good way to begin learning how policy processes operate. It is easy and free to set up a Google Alert with key words and receive notifications when relevant media is published. Public forums, seminars, conferences (professional and academic), community information sessions and public hearings are also important information sources, and provide diverse networking opportunities. Many professional and academic societies send out regular newsletters with relevant curated content and will notify their subscribers of such events. Social media (and particularly Twitter) is also a useful source of diverse information and is an important tool for ECRs to build their profile and networks.
We encourage ECRs to not feel pressured to immediately become an active contributor to policy discussions, whether it be online or in person. Time spent observing, listening and building a public profile is not wasted: it provides knowledge and skills that enables ECRs to learn 'where the action is' (Cairney and Oliver, 2017) and to make effective contributions to policy discourse with confidence. The knowledge and support of colleagues who have experience with interacting with policy processes is also invaluable, but identifying such individuals also requires time, effort and luck (see 'Relationships, networks and mentors').

\section{Build and maintain your public profile.}

"If you build it, he [they] will come."-Field of Dreams (1989)

As an ECR, connecting into policy discussions can appear like a chicken and egg problem: you need the expertise, reputation and relationships to gain access to relevant actors and networks, but you are usually too busy gaining expertise and scientific credibility (i.e., publishing science) to foster relationships. All scientists must navigate these trade-offs (Sarkki et al., 2014), but the stakes are higher for ECRs in an insecure job (Phillips and Heywood-Roos, 2015). One suggestion ${ }^{3}$ may be for ECRs to wait until they are in a more secure career position (i.e., tenured) before engaging in policy. However, this approach (which we do not advocate or support) is unlikely to satisfy ECRs who derive value and career satisfaction from policy engagement, and also diminishes the likelihood of unexpected opportunities that may arise through this engagement (e.g new contacts, ideas, collaborations, personal and professional development). Further, ECRs offer a wealth of knowledge and insights that may not be captured if "expertise" is defined only by status or years of experience (Burgman et al., 2011).

Establishing a strong online presence can kick-start efforts to build your profile and networks (Baker, 2015; Tachibana, 2014), and increase your perceived credibility and legitimacy among policy actors. There are many tools available to help with this, and at a minimum we suggest that all ECRs have a personal profile page embedded within their university web-page, and a Google Scholar account. Other popular options include a personal webpage/blog (using a platform such as Wordpress or Wix), LinkedIn, and Research Gate. Irrespective of which tools are used to build a public profile it is critical that they provide consistent and up to date information, including affiliation, profile photo, professional background, current research, and publications.

Further, the rise of social media has provided new opportunities for ECRs to establish their profile and build networks. Of all of the available platforms, Twitter is arguably the most influential for scientists, and provides a free and easy to use mechanism to enhance the reach and impact of your research (Christian, 2018; Darling et al., 2013; Eysenbach, 2011; Shuai et al., 2012; Thaler et al., 2012). Having an active presence on Twitter and other social media platforms is known to facilitate new relationships and networks with other scientists, as well as more diverse audiences including non-governmental organisations, private industry representatives, government agencies, journalists and other actors involved within policy and practice (Baker, 2015; Darling et al., 2013; Reed, 2016). Navigating social media can be daunting for those new to it, hence we encourage ECRs (and more senior scientists) to seek the advice of experienced colleagues and consult available guidance (e.g., Reed et al (2014) pp. 173-183) to learn how to maximise their use of Twitter with minimal effort (Shiffman, 2018) 
Actively contribute to policy discussions. The next step for ECRs on their pathway to impact is to begin to actively contribute towards policy discussions. There are a range of ways in which this can occur, whether it be online or in person, and through formal and informal channels. Underpinning all forms of engagement, however, are some fundamental principles that are worth emphasising:

- The (in)accessibility of primary science is a real and important barrier to knowledge exchange among scientists and decision-makers (Cvitanovic et al., 2014; Newman et al., 2017; Vilkins and Grant, 2017). However, it is important to remember that simply increasing access to, and supply of, information to policymakers will not automatically lead to "better" decisions (Cash et al., 2003; Evans et al., 2017; Sturgis and Allum, 2004; van Kerkhoff and Lebel, 2006).

- An extensive body of literature has emphasised that scientific evidence must be seen as credible, relevant and legitimate by policymakers for it to be considered in policy processes. To be legitimate, those who produce the information (e.g., scientists) must be seen as free from bias and trust-worthy (Dunn and Laing, 2017; Lacey et al., 2017; Pielke Jr, 2007; Sarkki et al., 2014)

- Before communicating, it is important to understand the goals and values of each actor, and align key messages with what the audience considers most relevant. While this can be relatively straight forward for one-to-one discussions, it is far more difficult when speaking to groups and larger audiences. One way to get around this is through 'story-telling', whereby a simple narrative (i.e., story) is used to convey key points. Such narratives will be most effective when combined with a personal anecdote that illustrates why a topic is important to the audience (Cairney and Kwiatkowski, 2017; Cairney and Oliver, 2017; Crow and Jones, 2018; Green et al., 2018)

- Even within seemingly homogenous groups of actors (e.g., members of a single industry body or government agency) there is often variation in the interests, values and modes of communication preferred by different individuals, so it is important to allow for flexibility in the approaches used to engage an audience

- A scientist's reputation is their currency. The manner in which a scientist (or any policy actor) conducts themselves will significantly enable (or limit) their ability to cultivate productive working relationships. We strongly suggest that ECRs ensure that at all times in any interaction, be it face-to face or online, they uphold the highest standards of professionalism, integrity and courtesy.

Some of the most effective ways to contribute to policy discussions are through informal channels: for example, meeting policymakers for discussions over coffee, sending colleagues working in government departments (who frequently do not have academic journal subscriptions (Newman et al., 2017; Vilkins and Grant, 2017) PDFs of relevant research articles with accompanying short lay summaries of the main findings, or offering to deliver a lunchtime seminar at a government agency (Kuehne et al., 2014). Such informal channels open up as networks and relationships develop (see 'Networks and mentors'). However, ECRs can begin fostering these networks and informal channels by initially adopting some less targeted approaches, including blogs, popular articles and policy submissions.

Blogs and other forms of "popular" writing (such as opinion pieces and news articles) which summarise and highlight the key findings from scientific research are an important resource for time-poor policymakers (Brisbois et al., 2018; Jackson et al., 2007; Kuehne et al., 2014). Many scientists choose to build their own websites that incorporate blog postings, but there are a range of established blog sites that scientists may contribute to. For example, the London School of Economics and Political Science 'Impact Blog' (http://blogs.lse.ac.uk/impactofsocialsciences/) and Research to Action (R2A, http://www.researchtoaction.org/) highlight research relating to the impact of science on policy and practice (and thus are also valuable resources from ECRs wanting to follow progress in this field). Writing for existing blogs can prove particularly beneficial as they are more likely to have an established audience and readership, as well as the means and tools to share your blog widely (e.g., via their website, mailing lists and Twitter accounts). They also typically employ an editor who can help tailor a blog for maximum impact and broadest appeal.

To be effective, blogs and popular articles must be short (maximum of 1000 words), free of unnecessary jargon, and convey one to two key messages. As with all forms of communication, it is important to consider the audience who will read it, and tailor the language and examples directly to them. Arguments must be substantiated and ideally linked back to the primary literature or other information sources (e.g., news articles) via hyperlinks in the text. To maximise exposure and encourage questions or comments, the article should conclude with a short section about the author, including a brief biography, Twitter handle and email address.

Notwithstanding the power of social media, not everyone is on Twitter-so it is important to consider the most suitable means of connecting with a range of audiences. Stories in the conventional news media can rapidly and markedly shape policy debates, and remain a crucial source of information for many policy actors. It is possible for your research to be picked up by the media from social media or a press release, but it is much more likely for this to occur if you actively pitch a story to a journalist. We suggest identifying journalists who write on topics relevant to your area of interest (e.g the health, environment or politics editor at a newspaper) and making a "cold call" (see "Relationships, networks and mentors' below). If a journalist's contact details are not readily available, we suggest making initial contact using a private message on Twitter, where many journalists are active.

A more formal means of contributing to policy discussions is to make a written submission to a government consultation process or enquiry. Government websites often provide a list of current public inquiries, and it is often possible to receive notifications of future calls for public submissions. Similar to writing a popular article, a policy submission must be clear, concise, and not be used as a vehicle for self-promotion. However, it needs to be formal in tone, link explicitly to the terms of reference of the consultation or enquiry, and provide clear recommendations (Australian Association of Social Workers, 2018; Australian Department of the House of Representatives, 2016; New Zealand Office of the Clerk of the House of Representatives, 2012). Policy submissions can also be used as a source for writing a blog or popular article, and also demonstrate a scientist's "impact" (which is increasingly a consideration in university promotion rounds) if their recommendations are cited in the enquiry report or the final policy.

Policy briefs are another medium for providing information to policy actors in a short, jargon-free format. They may be drafted for "in house" consumption (e.g by a civil servant to provide to their Minister), or published for wider distribution (e.g by think tanks, intergovernmental agencies and non-government organisations). A policy brief should succinctly describe a particular issue, argue why it represents a policy problem, and identify possible policy responses. (Balian et al., 2016; DeMarco and Tufts, 2014; Ffrench-Constant, 2014). Policy briefs may be used by a range of policy actors (NGO's, civil servants, government 
ministers, corporate executives) and at different levels (local, national, international), hence the length and content must be tailored to suit the audience. For instance, a policy brief for a government minister should be able to be read in the time taken in an elevator ride (K. Hussey, pers. comm., 2015). Policy briefs are most effective when sent directly to specific policy actors, but it is important to ensure a relationship is established with the relevant individual(s) beforehand as unsolicited policy briefs are unlikely to be well received.

Relationships, networks and mentors. "Build relationships" is the oft-cited guidance offered to scientists who want to enhance their impact on policy and practice (Brisbois et al., 2018; Cairney et al., 2016; Gibbons et al., 2008). While this is undoubtedly good advice, policy actors will vary in how difficult they are to gain access to, and how valuable their skills and experience will be at particular points in time. For example, it is highly unlikely that a scientist could establish direct contact with a government minister without many years of networking and dialogue with civil servants - and indeed, building relationships with more junior policymakers will often be more effective for ECRs initially (Brisbois et al., 2018).

Relationships do not appear out of thin air. It is possible, however, to create the conditions necessary to foster effective relationships with policymakers and other actors. Adopting some or all of the strategies discussed so far in this paper will help ECRs to learn 'where the action is' (Cairney and Oliver 2017) and to gain a 'seat at the table'. The role of luck and chance encounters at conferences, random social events and on social media also cannot be overstated. However, there are some steps ECRs can take to actively improve the diversity and quality of their networks.

First, think about your immediate network: colleagues, collaborators, supervisors, even friends and family. Reed (2016) refers to this group of individuals as your 'influence network'. Consider whether they may have relevant connections, and ask whether they may feel comfortable making an introduction for you. Bear in mind that effective, mutually beneficial relationships with policy actors are hard won and can take many years to foster and maintain. Do not expect your colleagues to open up their whole address book for you, and ensure you recognise the trust they have placed in you and approach this new relationship with care and respect. Broadening your network via mutual connections is akin to "snowball sampling" used by social researchers (Biernacki and Waldorf, 1981), and similar principles apply to your professional networking (maintain confidence, mutual respect, trust).

An important, complementary approach is to "cold call" and reach out to individuals with whom you have no mutual connections. This can be a particularly daunting exercise, and can either reap huge rewards, or not eventuate into anything useful. When "cold" contacting individuals, we suggest to first send them an email which briefly introduces yourself (organisation, position, one sentence description of your research interest), and clearly articulates why you are contacting them (e.g., you read their article, they work for a relevant organisation), and what you want from them (e.g., meet for coffee, arrange a phone call, answer a specific question). Consider what you have to offer them, and what you are willing to provide. If you are simply interested in their perspective, be humble, gracious, and clearly communicate that you value their time and insights. Similarly, ensure your responses to those who reach out to you are timely and respectful. Remember that everyone is time-poor, and this person needs to be convinced that interacting with you will be beneficial or at least neutral to them.
Finally, all ECRs should identify and foster relationships with individuals from diverse sectors (i.e., not just academia) who can act as mentors (Clifford et al., 2014). A range of formal mentoring programs exist, including some which are specific to enhancing links between science and policy (see 'Internships, fellowships and other science policy opportunities'). However, mentoring relationships frequently develop informally and are rarely clearly signified by an official "mentor" status or label. Indeed, you may already be mentored by one or more people without quite realising it (Sandberg, 2013). In the time spent observing policy debate and listening to views expressed in range of fora (see 'Identify who is involved with policy processes, and why'), it is likely you will come across individuals from a range of backgrounds who are willing to offer you advice and support.

Mentors can provide mentees with a range of benefits (Allen et al., 2004), including access to networks and hard-won 'inside' knowledge of policy processes. Successful mentor-mentee relationships are, however, built on reciprocity and two-way exchange, as well as mutual respect, clear expectations, and shared values (Haggard et al., 2011; Straus et al., 2013). We suggest that ECRs apply the same logic to identifying and fostering potential mentoring relationships in the same way as any other policy actor (as described in this section), as such individuals are more likely to emerge naturally over time, rather than through an out-of-the-blue introduction and request to "be my mentor" (Sandberg, 2013).

Internships, fellowships and other science policy opportunities. In the pursuit of developing scientists who understand and can effectively engage with policy processes (Tyler, 2017), many organisations now offer formal opportunities for scientists to learn about and experience policymaking in practice (AAAS, 2017; Bernstein et al., 2017; Kuehne et al., 2014; Petes and Meyer, 2018). These provide important avenues for ECRs to gain firsthand experience of operating at the interface of science and policy. Analysis conducted by American Association for the Advancement of Science (AAAS) identified more than 150 science policy internships, fellowships, placements and other opportunities across nearly 50 countries (AAAS, 2017).

Table 3 provides a selection of such opportunities (full list available at: https://osf.io/hfwqr/), which vary in duration and suitability for different career stages. For example, internships are generally targeted at undergraduate and graduate students, may run for a few months to a year, and may embed the intern directly within a government department, industry association or nongovernment organisation. Fellowships more typically cater for researchers within 5 years of $\mathrm{PhD}$ completion, and may incorporate a more substantial research component alongside policy-related activities (AAAS, 2017). If there are no formal opportunities advertised in your area of interest, it may be possible to create an opportunity. Ask a mentor or your professional society to advocate for you and approach a government department to take you on for a short period, for example a summer research project.

\section{Personal attributes for achieving impact}

To conclude this paper, we will outline some of the critical personal skills and attributes that are necessary in individuals seeking to influence policy and practice. Indeed, having the right personal qualities is recognised as a key factor underpinning impact at this interface (Cvitanovic et al., 2016). However, in doing so, we seek to move beyond the articulation of the 'typical' and obvious features that are well established in the literature (e.g., strong communication skills, understanding of both science and policy contexts, expansive stakeholder networks, etc.). While such skills 


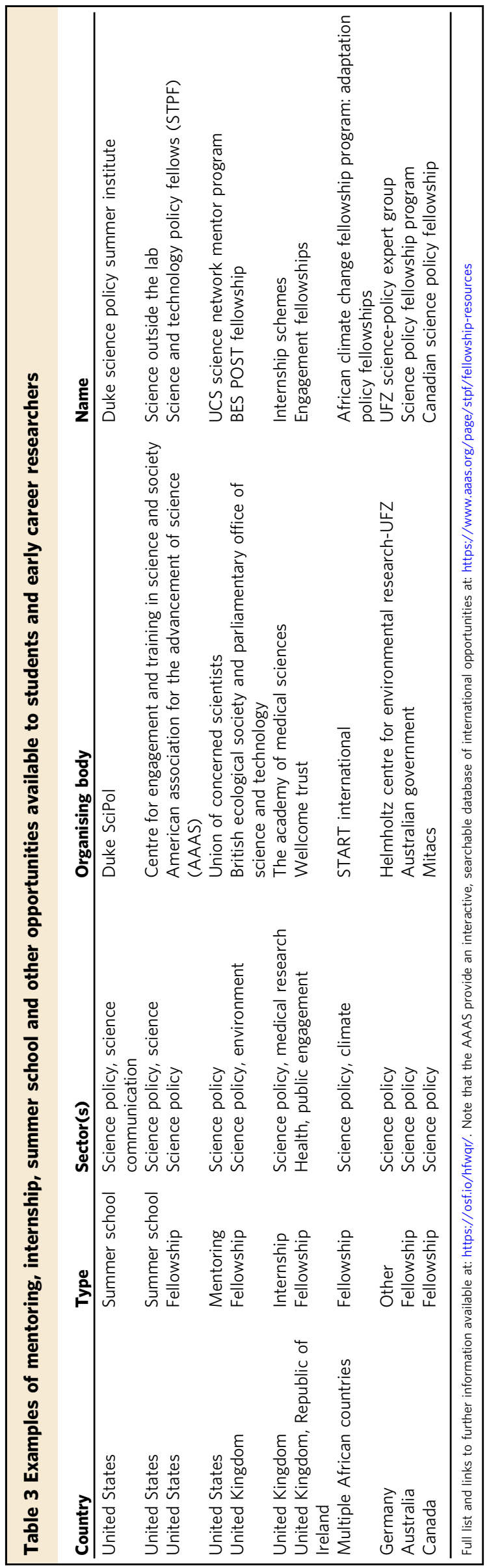

are certainly important as we have highlighted throughout various parts of this manuscript, here we draw on our personal experiences working at the interface of science and policy and articulate the secondary (or soft) skills that are required but not often discussed in the literature or taught in academic training. Specifically, we will explore the importance of honesty, humility, openness and resilience.

Honesty. Arguably one of the most important attributes of individuals who successfully influence policy and practice is that of honesty - a necessary precondition to building trust with the various actors that you are seeking to influence. Indeed, dishonest or untrustworthy behaviour can severely jeopardise the potential to have impact on policy and practice. For example, at the individual level, dishonest behaviour may erode the extent to which an individual decision-maker (or group of decision-makers) trusts you, reducing the likelihood that they will actively engage with you and/or incorporate your research and/or knowledge into their decision-making processes (Stern and Coleman, 2015). Furthermore, a major breach in trust through dishonest behaviour may have broader and potentially irreversible ramifications for your organisation's reputation and limit the ability of your colleagues to have impact on policy and practice (Lacey et al., 2018).

While the importance of honesty may seem intuitive, and most scientists would consider themselves as honest individuals, communicating science has inherent challenges that may lead to dishonest actions (either consciously or unconsciously) (Cairney and Oliver, 2017; Lacey et al., 2015; Pielke Jr, 2007). For example, limited funding opportunities and the (unfortunately) persistent 'publish or perish' culture of science may lead an individual scientists to singularly promote themselves or their own stream of research to decision-makers, rather than informing them of the full suite of information upon which they could base their decision (Lacey et al., 2015). This, in turn, may transfer risk to the decision-maker and limit the success of their actions.

In promoting honesty as a key individual attribute for impact on policy and practice, we encourage ECRs and all scientists to follow Pielke's (2007) description of an honest broker, whereby when engaging with decision-makers and other actors, care is taken to not advocate for a single cause or predetermined outcome (see also Jasanoff, 2008). Rather, you present the full suite of available options and perspectives that are available to inform the decision-making process. In doing so you should also take steps to ensure complete transparency and accountability, in that you declare any biases (e.g., those associated with a funding body or a personal affiliation) at the beginning of the conversation, and are open and honest as to the limitations of your knowledge base and experiences (Lacey et al., 2018). If you learn that you have inadvertently provided false or misleading information to a decision-maker it is important to act quickly to remedy the situation before trust is broken. This can be achieved by following the principles of trust repair (Gillespie and Dietz, 2009), whereby you immediately acknowledge the error, communicate the cause of the error to the decision-maker and implement steps to prevent the situation from happening again.

Humility. Humility refers to the state or quality of being humble, whereby an individual does not have an over inflated sense of self-worth or arrogance. Such individuals recognise that the worldviews, beliefs and knowledge bases of all actors are important and seek to cultivate a working relationship that respects and incorporates the views of everyone equally, opposed to asserting their individual perspectives. Evidence from a range of sectors has highlighted the importance of humility as an essential 
precondition of meaningful engagement and trust building (e.g., Duchelle et al., 2009; Hook et al., 2013; Wright et al., 2016), which underpins impact on policy and practice. Unlike a range of the other personal attributes needed to have impact on policy and practice (e.g., communication skills, writing skills, policy nous, etc.), humility cannot be taught or mastered - it is largely an inherent quality within each individual. However, there are a range of strategies that you should consider, and adopt, to help you act with humility.

Firstly, you should be situationally aware, whereby you have an understanding and respect of the various actors, their beliefs, their individual and institutional constraints and their social dynamics. Being situationally aware also means that you understand your place/role in the group and first seek to understand the views and opinions of others and understand where there is opportunity for convergence. To do so you should first start by observing the policy context (see 'Understanding policy in practice') and actively listening to the views being expressed by diverse actors, with particular attention being paid to marginal voices and 'unusual suspects' (Colvin et al., 2016). If any of these views challenge your own beliefs, ask questions to better understand what is driving their perspective. This may entail navigating ambiguity (Cairney et al., 2016) (particularly when dealing with policy processes), but embrace this ambiguity and see it as an opportunity for collaboration and learning (in both directions) opposed to a road block (Fleming and Howden, 2016). Finally, accept setbacks, admit mistakes and take time to self-reflect to learn from your interactions.

Openness. It is also critical to be 'open':open to learning, open to new ways of doing things, and open to feedback and criticism. Being open in this manner can be particularly challenging for ECRs who have been trained in accordance to the rules and norms of a single discipline that may not recognise the methods and approaches of other disciplines (e.g., long-standing issues of integrating natural and social sciences, (Moon and Blackman, 2014)). Yet openness is a personal trait that is crucial to foster, as it is linked to the extent to which you can cultivate productive, meaningful and sustained working relationships with other individuals (Wright et al., 2016). Openness is also linked to innovation, as it increases the extent to which divergent views among actors are converged early in discussions to solve complex problems (Love et al., 2011).

As we have emphasised throughout this paper, there is no onesize-fits-all approach to achieving impact on policy and practice. Rather, impacts will only be achieved by tailoring and refining your approach and strategies to specific contexts, which can be further complicated when contexts change (e.g., change of government leadership, change of organisational directive, etc.). Navigating this type of complexity successfully requires you to be open to learning, open to accepting feedback and criticism and open to adapting your approach and strategies based on your learnings as necessary (Newig et al., 2010).

Resilience. Finally, and perhaps most importantly, achieving realworld impact requires resilience (Graber et al., 2015; Southwick et al., 2014). Your pathway to impact will include a range of challenges, failures, and individuals who will make you doubt yourself, your ability, and even the value of your goals themselves. You are also likely to encounter situations that challenge your personal morals and/or professional ethics, or individuals who may seek to manipulate you for self-gain. Persevering through these obstacles is not easy - and there will be times that you want to give up. We all go through this.
Working to achieve policy impact in science is hard, and especially for ECRs (Phillips and Heywood-Roos, 2015; Sarkki et al., 2014). The key is to remind yourself of why you are motivated to make an impact in the first place (Reed, 2016, 2017). We encourage you to stay focused on your goals, what drives you as an individual, and what you want to achieve. Make time to celebrate the small wins, no matter how small they are (e.g., developing a research impact plan, establishing a new relationship, etc.). Look after your mental health (Evans et al., 2018; Nature 2018), and take breaks from your impact work when needed. Surround yourself with good people - people who share your values and goals, people who encourage, inspire, and support you.

\section{Conclusions}

In this paper, we have sought to provide an accessible guide for ECRs who wish to engage more effectively with policy and practice. Achieving policy 'impact' is a difficult, long-term, often thankless endeavour; but one which offers both personal and professional rewards. Society increasingly demands that scientists demonstrate the positive impacts from their work, and the university sector is beginning to respond (Boswell and Smith, 2017; Sivertsen, 2017). It is, however, likely that scientists will need to balance the conflicting pressures of demonstrating impact and 'publish or perish' for the foreseeable future (Keeler et al., 2017; Tyler, 2017; Wittemyer et al., 2018). ECRs offer a wealth of experiences, insights and expertise that may be missed if only senior, tenured scientists are supported and encouraged to engage with policy processes. While ECRs undoubtedly face additional challenges in navigating these trade-offs (Phillips and HeywoodRoos, 2015; Sarkki et al., 2014), our hope is that the guidance we have offered here provides a basis from which ECRs can create their own pathways to impact.

Received: 13 March 2018 Accepted: 18 June 2018

Published online: 10 July 2018

\section{Notes}

1 In this paper, we define "impact" in its broadest sense as the positive and demonstrable benefits that can be attributed to scientific research. Following this definition, impacts could be characterised in a number of ways including; instrumental impacts, conceptual impacts, attitudinal impacts, cultural impacts, and/or impacts related to capacity building and preparedness. For a comprehensive list of the types of impacts that can be generated, we refer the reader to (Reed et al., 2018). Note that the UK REF (Research Excellence Framework, 2014) defines "impact" as the demonstrable and positive effects of scientific research beyond academia, such as those to the economy, society, culture, public policy or services, health, the environment or quality of life. The Australian Research Council (ARC) has adopted the REF definition for its 2018 Engagement and Impact (EI) assessment (Commonwealth of Australia, 2018).

2 In November 2017, the Australian Network of Environmental Social Scientists (NESS) held an event at the University of Queensland that brought together diverse speakers across the spectrum of policy, practice and academia to share their experiences and provide insights for researchers working to achieve real-world impact through their research. Further details can be found at: http://www.nessaustralia.org/2017/11/14/ highlights-2017-ness-forum/

3 Both of the authors have, at multiple times, been advised to "focus on publishing for now and wait until you get to Professor" before engaging with policy, by well-meaning and very senior academics. Both of the authors have so far ignored this advice, though cannot yet say with certainty whether this has been a wise career decision in terms of our longevity and success in academia. We do feel, however, that engaging with policy processes early in our careers has been incredibly satisfying on a personal level.

\section{References}

AAAS (2017) Connecting scientists to policy around the world: landscape analysis of mechanisms around the world engaging scientists and engineers in policy. Washington, D.C.: American Association forthe Advancement of Science. aaas.org/GlobalSciencePolicy 
Allen TD, Eby LT, Poteet ML et al. (2004) Career benefits associated with mentoring for proteges: a meta-analysis. J Appl Psychol 89(1):127-136. https:// doi.org/10.1037/0021-9010.89.1.127

Arlettaz R, Schaub M, Fournier J et al. (2010) From publications to public actions: when conservation biologists bridge the gap between research and implementation. Bioscience 60(10):835-842. https://doi.org/10.1525/bio.2010.60.10.10

Australian Association of Social Workers (2018) How to develop a policy submission. https://www.aasw.asn.au/social-policy-advocacy/how-to-developand-write-a-policy-submission Accessed 13 March 2018

Australian Department of the House of Representatives (2016) Making a submission to a committee inquiry. https://www.aph.gov.au/Parliamentary_Business/ Committees/House/Making_a_submission Accessed 13 March 2018

Baker M (2015) Social media: a network boost Nature 518(7538):263-265. https:// doi.org/10.1038/nj7538-263a

Balian EV, Drius L, Eggermont $\mathrm{H}$ et al. (2016) Supporting evidence-based policy on biodiversity and ecosystem services: recommendations for effective policy briefs. Evid Policy 12(3):431-451. https://doi.org/10.1332/174426416X14700777371551

Bednarek AT, Wyborn C, Cvitanovic C, et al. (2018) Boundary spanning at the science-policy interface: the practitioners' perspectives. Sustain Sci 1-9 https://doi.org/10.1007/s11625-018-0550-9

Bernstein MJ, Reifschneider K, Bennett I et al. (2017) Science outside the lab: helping graduate students in science and engineering understand the complexities of science policy. Sci Eng Ethics 23(3):861-882. https://doi.org/ 10.1007/s11948-016-9818-6

Biernacki P, Waldorf D (1981) Snowball sampling: problems and techniques of chain referral sampling. Sociol Methods Res 10(2):141-163. https://doi.org/ $10.1177 / 004912418101000205$

Boswell C, Smith K (2017) Rethinking policy 'impact': four models of research-policy relations. Pal Commun 3(1):44. https://doi.org/10.1057/s41599-017-0042-z

Box GEP (1976) Science and statistics. J Am Stat Assoc 71(356):791-799. https:// doi.org/10.1080/01621459.1976.10480949

Bridgman P, Davis G (2000) The Australian Policy Handbook. N.S.W.: Allen \& Unwin Bridgman P, Davis G (2003) What use is a policy cycle? Plenty, if the aim is clear. Aust J Public Adm 62(3):98-102

Brisbois MC, Girling K, Findlay S (2018) Academics should build rapport with government's policy analysts. Nature 555(7695):165-165. https://doi.org/ 10.1038/d41586-018-02831-3

Burgman M, Carr A, Godden L et al. (2011) Redefining expertise and improving ecological judgment. Conserv Lett 4(2):81-87. https://doi.org/10.1111/j.1755263X.2011.00165.x

Cairney P (2011) Understanding public policy: theories and Issues. 2011 edition. Houndmills. Palgrave, Basingstoke, Hampshire; New York

Cairney P (2016) The politics of evidence-based policy making, 1st edn. Palgrave Pivot, New York, p 20

Cairney P, Heikkila T (2014) A Comparison of Theories of the Policy Process. In: Sabatier PA, Weible CM (eds) Theories Policy Proc. 3. Westview Press, Boulder, Colorado, pp 363-389

Cairney P, Kwiatkowski R (2017) How to communicate effectively with policymakers: combine insights from psychology and policy studies. Pal Commun 3 (1): 37. https://doi.org/10.1057/s41599-017-0046-8

Cairney P, Oliver K (2017) Evidence-based policymaking is not like evidence-based medicine, so how far should you go to bridge the divide between evidence and policy? https://doi.org/10.1186/s12961-017-0192-x

Cairney P, Oliver K, Wellstead A (2016) To bridge the divide between evidence and policy: reduce ambiguity as much as uncertainty. Public Adm Rev 76 (3):399-402. https://doi.org/10.1111/puar.12555

Caplan N (1979) The two-communities theory and knowledge utilization. Am Behav Sci 22(3):459-470. https://doi.org/10.1177/000276427902200308

Cash DW, Clark WC, Alcock F et al. (2003) Knowledge systems for sustainable development. Proc Natl Acad Sci 100(14): 8086-8091 https://doi.org/10.1073/ pnas. 1231332100

Christian K (2018) Communicating your research: get it right, do it often. It really matters. http://blogs.nature.com/naturejobs/2018/03/30/communicatingyour-research-get-it-right-do-it-often-it-really-matters/ Accessed 2 May 2018

Clifford PS, Fuhrmann CN, Lindstaedt B et al. (2014) Getting the mentoring you need. Science Careers http://www.sciencemag.org/careers/2014/01/gettingmentoring-you-need, https://doi.org/10.1126/science.caredit.a1400027

Cohen MD, March JG, Olsen JP (1972) A garbage can model of organizational choice. Adm Sci Q 17(1):1-25. https://doi.org/10.2307/2392088

Colvin RMM, Witt GB, Lacey J (2016) Approaches to identifying stakeholders in environmental management: Insights from practitioners to go beyond the 'usual suspects'. Land Use Policy 52:266-276. https://doi.org/10.1016/J. LANDUSEPOL.2015.12.032

Commonwealth of Australia (2018) Australian Research Council-EI 2018 Framework. Canberra, Australia

Cornell S, Berkhout F, Tuinstra W et al. (2013) Opening up knowledge systems for better responses to global environmental change. Environ Sci Policy 28:60-70. https://doi.org/10.1016/J.ENVSCI.2012.11.008
Crow D, Jones M (2018) Narratives as tools for influencing policy change. 46(2): 217-234 https://doi.org/10.1332/030557318X15230061022899

Cvitanovic C, Fulton CJ, Wilson SK et al. (2014) Utility of primary scientific literature to environmental managers: an international case study on coraldominated marine protected areas. Ocean Coast Manag 102:72-78. https:// doi.org/10.1016/J.OCECOAMAN.2014.09.003

Cvitanovic C, Hobday AJ, van Kerkhoff L, Wilson SK et al. (2015) Improving knowledge exchange among scientists and decision-makers to facilitate the adaptive governance of marine resources: a review of knowledge and research needs. Ocean Coast Manag 112:25-35. https://doi.org/10.1016/j. ocecoaman.2015.05.002

Cvitanovic C, Hobday AJ, van Kerkhoff L, Marshall NA (2015) Overcoming barriers to knowledge exchange for adaptive resource management; the perspectives of Australian marine scientists. Mar Policy 52:38-44. https://doi. org/10.1016/j.marpol.2014.10.026

Cvitanovic C, McDonald J, Hobday AJ (2016) From science to action: principles for undertaking environmental research that enables knowledge exchange and evidence-based decision-making. J Environ Manag 183(Part 3):864-874. https://doi.org/10.1016/j.jenvman.2016.09.038

Darling ES, Shiffman D, Côté IM et al. (2013) The role of Twitter in the life cycle of a scientific publication. PeerJ Inc. https://doi.org/10.7287/peerj.preprints.16vl

Davis G (1993) Public policy in Australia. Allen \& Unwin, Sydney

DeMarco R, Tufts KA (2014) The mechanics of writing a policy brief. Nurs Outlook 62(3):219-224. https://doi.org/10.1016/j.outlook.2014.04.002

Dovers S, Hussey K (2013) Environment and sustainability: a policy handbook, 2nd edn. The Federation Press, Annandale, NSW

Duchelle AE, Biedenweg K, Lucas C et al. (2009) Graduate students and knowledge exchange with local stakeholders: possibilities and preparation. Biotropica 41 (5):578-585. https://doi.org/10.1111/j.1744-7429.2009.00563.x

Dunlop CA, Radaelli CM (2018) The lessons of policy learning: strategies, triggers, hindrances and pathologies. Policy Polit 46(2):255-726. https://doi.org/ $10.1332 / 030557318 X 15230059735521$

Dunn G, Laing M (2017) Policy-makers perspectives on credibility, relevance and legitimacy (CRELE). Environ Sci Policy 76:146-152. https://doi.org/10.1016/j. envsci.2017.07.005

Evans MC, Davila F, Toomey A et al. (2017) Embrace complexity to improve conservation decision making. Nat Ecol Evol 1(11) 1588 https://doi.org/ 10.1038/s41559-017-0345-x

Evans TM, Bira L, Gastelum JB et al. (2018) Evidence for a mental health crisis in graduate education. Nat Biotechnol 36(3):282-284. https://doi.org/10.1038/ nbt. 4089

Everett S (2003) The policy cycle: democratic process or rational paradigm revisited? Aust J Public Adm 62(2):65-70. https://doi.org/10.1111/1467-8497.00325

Eysenbach G (2011) Can tweets predict citations? Metrics of social impact based on Twitter and correlation with traditional metrics of scientific impact. J Med Internet Res 13(4):e123. https://doi.org/10.2196/jmir.2012

Fazey I, Evely AC, Reed MS et al. (2013) Knowledge exchange: a review and research agenda for environmental management. Environ Conserv https:// doi.org/10.1017/S037689291200029X

Ffrench-Constant L (2014) How to plan, write and communicate an effective policy brief: three steps to success. http://www.researchtoaction.org/2014/10/planwrite-communicate-effective-policybrief-three-steps-success/

Fleming A, Howden SM (2016) Ambiguity: a new way of thinking about responses to climate change. Sci Total Environ 571:1271-1274. https://doi.org/10.1016/ J.SCITOTENV.2016.07.162

Gibbons P, Zammit C, Youngentob K et al. (2008) Some practical suggestions for improving engagement between researchers and policy-makers in natural resource management. Ecol Manag Restor 9(3):182-186. https://doi.org/ $10.1111 / j .1442-8903.2008 .00416 . x$

Gillespie N, Dietz G (2009) Trust repair after an organization-level failure. Acad Manag Rev 34(1):127-145

Gluckman P (2016) The science-policy interface. Science 353(6303): 969 https:// doi.org/10.1126/science.aai8837

Graber R, Pichon F, Carabine E (2015) Psychological resilience: State of knowledge and future research agenda. Overseas Development Institute, London

Green SJ, Grorud-Colvert K, Mannix H (2018) Uniting science and stories: perspectives on the value of storytelling for communicating science. In: Shanahan M-C (ed) FACETS 3(1). Canadian Science Publishing, Ottawa, pp 164-173

Haggard DL, Dougherty TW, Turban DB et al. (2011) Who is a mentor? A review of evolving definitions and implications for research. J Manag 37(1):280-304. https://doi.org/10.1177/0149206310386227

Head BW (2008) Three lenses of evidence-based policy. Aust J Public Adm 67 (1):1-11. https://doi.org/10.1111/j.1467-8500.2007.00564.x

Hogwood BW, Gunn LA (1984) Policy analysis for the real world. Oxford University Press, Oxford, U.K.

Hook JN, Davis DE, Owen J et al. (2013) Cultural humility: measuring openness to culturally diverse clients. J Couns Psychol 60(3):353-366. https://doi.org/ 10.1037/a0032595 
Howlett M, Ramesh M, Perl A (2009) Studying public policy: policy cycles and policy subsystems, 3rd edn. Oxford University Press, New York

Jackson A, Yates J, Orlikowski W (2007) Corporate Blogging: Building community through persistent digital talk. In: 2007 40th Annual Hawaii International Conference on System Sciences (HICSS'07), IEEE, p 80

Jasanoff S (2008) Speaking honestly to power. Am Sci 96(3):240-243

Keeler BL, Chaplin-Kramer R, Guerry AD et al. (2017) Society is ready for a new kind of science-is academia? Bioscience 67(7):591-592. https://doi.org/ 10.1093/biosci/bix051

Kellard NM, Śliwa M (2016) Business and management impact assessment in research excellence framework 2014: analysis and reflection. Br J Manag 27 (4):693-711. https://doi.org/10.1111/1467-8551.12186

Kingdon JW (1984) Agendas, alternatives, and public policies | Clc. Little, Brown

Klein E (2009, December 29) A more partisan politics with more bipartisan results. The Washington Post

Kuehne LM, Twardochleb LA, Fritschie KJ et al. (2014) Practical science communication strategies for graduate students. Conserv Biol 28(5):1225-1235. https://doi.org/10.1111/cobi.12305

Lacey J, Howden SM, Cvitanovic C et al. (2015) Informed adaptation: ethical considerations for adaptation researchers and decision-makers. Glob Environ Change 32:200-210. https://doi.org/10.1016/J.GLOENVCHA.2015.03.011

Lacey J, Howden M, Cvitanovic C et al. (2017) Understanding and managing trust at the climate science-policy interface. Nat Clim Change $1 \mathrm{https} / /$ doi.org/ 10.1038/s41558-017-0010-z

Lacey J, Howden M, Cvitanovic C et al. (2018) Understanding and managing trust at the climate science-policy interface. Nat Clim Change 8(1):22-28. https:// doi.org/10.1038/s41558-017-0010-z

Lasswell HD (1971) A pre-view of policy sciences. American Elsevier Publishing, New York

Laundon M (2017) PhD students should be taught more about research impact and engagement. http://blogs.lse.ac.uk/impactofsocialsciences/2017/12/18/phdstudents-should-be-taught-more-about-research-impact-and-engagement/ Accessed 9 May 2018

Lee KN (1993) Compass and gyroscope: integrating science and politics for the environment. Island Press, Washington

Love JH, Roper S, Bryson JR (2011) Openness, knowledge, innovation and growth in UK business services. Res Policy 40(10):1438-1452. https://doi.org/ 10.1016/J.RESPOL.2011.05.016

Lubchenco J (1998) Entering the century of the environment: a new social contract for science. Science 279(5350):491-497. https://doi.org/10.1126/ science.279.5350.491

Malhi Y, Roberts JT, Betts RA et al. (2008) Climate change, deforestation, and the fate of the Amazon. Science 319(5860):169-72

Marcella R, Lockerbie H, Bloice L et al. (2017) The effects of the research excellence framework research impact agenda on early- and mid-career researchers in library and information science. SAGE Publications, UK, London, England, 0165551517724685

Marshall N, Adger N, Attwood S et al. (2017) Empirically derived guidance for social scientists to influence environmental policy. PLoS One 12(3):e0171950. https://doi.org/10.1371/journal.pone.0171950

Mekonnen MM, Hoekstra AY (2016) Four billion people facing severe water scarcity. Sci Adv 2(2):e1500323-e1500323. https://doi.org/10.1126/ sciadv. 1500323

Moon K, Blackman D (2014) A guide to understanding social science research for natural scientists. Conserv Biol 28(5):1167-1177. https://doi.org/10.1111/ cobi. 12326

Murphy T (2017) Revising the research excellence framework: ensuring quality in REF2021, or new challenges ahead? Perspectives 21(1):34-39. https://doi.org/ 10.1080/13603108.2016.1246386

Nash KL, Cvitanovic C, Fulton EA et al. (2017) Planetary boundaries for a blue planet. Nat Ecol \& Evol 1(11):1625-1634. https://doi.org/10.1038/s41559017-0319-z

Nature (2018) Editorial: Time to talk about why so many postgrads have poor mental health. Nature 556(7699):5-5. https://doi.org/10.1038/d41586-01804023-5

New Zealand Office of the Clerk of the House of Representatives (2012) Making a submission to a parliamentary select committee

Newig J, Günther D, Pahl-Wostl C (2010) Synapses in the network: learning in governance networks in the context. Ecol Soc 15(4). https://doi.org/10.1197/ jamia.M2385

Newman J, Cherney A, Head BW (2016) Do policy makers use academic research? reexamining the "two communities" theory of research utilization. Public Adm Rev 76(1):24-32. https://doi.org/10.1111/puar.12464

Newman J, Cherney A, Head BW (2017) Policy capacity and evidence-based policy in the public service. Public Manag Rev 19(2):157-174. https://doi.org/ 10.1080/14719037.2016.1148191

North DC (1991) Institutions. J Econ Perspect 5(1):97-112
Oliver K, Pearce W (2017) Three lessons from evidence-based medicine and policy: increase transparency, balance inputs and understand power. Palgrave Commun 3(1):43. https://doi.org/10.1057/s41599-017-0045-9

Pecl GT, Araújo MB, Bell JD et al. (2017) Biodiversity redistribution under climate change: Impacts on ecosystems and human well-being. Science 355(6332): eaai9214. https://doi.org/10.1126/science.aai9214

Petes LE, Meyer MD (2018) An ecologist's guide to careers in science policy advising. Front Ecol Environ 16(1): 53-54 https://doi.org/10.1002/fee.1761

Phillips S, Heywood-Roos R (2015) Job security for early career researchers is a significant factor in helping research make an impact. Impact Soc Sci http:// blogs.lse.ac.uk/impactofsocialsciences/2015/06/30/early-career-paths-ofdoctorate-holders-esf-pilot/ Accessed 12 January 2018.

Pielke Jr RA (2007) The honest broker: making sense of science in policy and politics. Cambridge University Press, Cambridge; New York

Pietri DM, Gurney GG, Benitez-Vina N et al. (2013) Practical recommendations to help students bridge the research-implementation gap and promote conservation. Conserv Biol 27(5):958-967. https://doi.org/10.1111/cobi.12089

Reed M (2016) The research impact handbook. Fast Track Impact, Aberdeenshire, UK

Reed MS (2017) The productive researcher. Fast Track Impact, Aberdeenshire, UK

Reed MS, Graves A, Dandy N et al. (2009) Who's in and why? A typology of stakeholder analysis methods for natural resource management. J Environ Manag 90(5):1933-1949. https://doi.org/10.1016/j.jenvman.2009.01.001

Reed MS, Stringer LC, Fazey I et al. (2014) Five principles for the practice of knowledge exchange in environmental management. J Environ Manag 146:337-345. https://doi.org/10.1016/j.jenvman.2014.07.021

Reed MS, Bryce M, Machen R (2018) Pathways to policy impact: a new approach for planning and evidencing research impact. Evidence Policy

Research Excellence Framework (2014) Research Excellence Framework 2014: The results. Bristol

Rose DC, Mukherjee N, Simmons BI et al. (2017) Policy windows for the environment: Tips for improving the uptak0065 of scientific knowledge. Environ Sci Policy. https://doi.org/10.1016/j.envsci.2017.07.013.

Rubin R (2002) Will the real SMART goals please stand up. The industrialorganizational. Psychologist 39(4):26-27. https://doi.org/10.1080/ 13604810802479126

Sandberg S (2013) Chapter 5: Are you my mentor? In: Knopf AA Lean in : Women, Work, and the Will to Lead. Alfred A. Knopf, New York, NY, p 240

Sarkki S, Niemelä J, Tinch R et al. (2014) Balancing credibility, relevance and legitimacy: critical assessment of trade-offs in science-policy interfaces. Sci Public Policy 41(2):194-206. https://doi.org/10.1093/scipol/sct046

Shiffman DS (2018) Social media for fisheries science and management professionals: how to use it and why you should. Fisheries 43(3):123-129. https:// doi.org/10.1002/fsh.10031

Shonkoff JP (2000) Science, policy, and practice: three cultures in search of a shared mission. Child Dev 71(1):181-187. https://doi.org/10.1111/1467-8624.00132

Shuai X, Pepe A, Bollen J (2012) How the scientific community reacts to newly submitted preprints: article downloads, twitter mentions, and citations. PLoS One 7(11):e47523. https://doi.org/10.1371/journal.pone.0047523

Sivertsen G (2017) Unique, but still best practice? The Research Excellence Framework (REF) from an international perspective. Palgrave Commun 3:17078. https://doi.org/10.1057/palcomms.2017.78

Smith KE, Stewart E (2017) We need to talk about impact: why social policy academics need to engage with the UK's research impact agenda. J Soc Policy 46(1):109-127. https://doi.org/10.1017/S0047279416000283

Southwick SM, Bonanno GA, Masten AS et al. (2014) Resilience definitions, theory, and challenges: Interdisciplinary perspectives. Eur J Psychotraumatol 5 (1):25338. https://doi.org/10.3402/ejpt.v5.25338

Stein F (2018) Anthropology's 'impact': a comment on audit and the unmeasurable nature of critique. J R Anthropol Inst 24(1):10-29. https://doi.org/10.1111/ $1467-9655.12749$

Stern MJ, Coleman KJ (2015) The multidimensionality of trust: applications in collaborative natural resource management. Soc Nat Resour 28(2):117-132. https://doi.org/10.1080/08941920.2014.945062

Straus SE, Johnson MO, Marquez C et al. (2013) Characteristics of successful and failed mentoring relationships: a qualitative study across two academic health centers. Acad Med 88(1):82-9. https://doi.org/10.1097/ACM.0b013e31827647a0

Sturgis P, Allum N (2004) Science in society: re-evaluating the deficit model of public attitudes. Public Underst Sci 13(1):55-74. https://doi.org/10.1177/ 0963662504042690

Sutherland WJ, Wordley CFR (2017) Evidence complacency hampers conservation. Nature Ecol Evol 1. https://doi.org/10.1038/s41559-017-0244-1.

Sutherland WJ, Pullin AS, Dolman PM et al. (2004) The need for evidence-based conservation. Trends Ecol Evol 19(6):305-308. https://doi.org/10.1016/j. tree.2004.03.018

Tachibana C (2014) A scientist's guide to social media. Science. http://www. sciencemag.org/features/2014/02/scientists-guide-social-media Accessed 12 Jan 2018. 
Tai APK, Martin MV, Heald CL (2014) Threat to future global food security from climate change and ozone air pollution. Nat Clim Change 4(9):817-821. https://doi.org/10.1038/nclimate2317

Thaler AD, Zelnio KA, Freitag A et al. (2012) Digital environmentalism: Tools and strategies for the evolving online ecosystem. In: Gallagher D (ed.) Environmental leadership: a reference handbook. SAGE Publications, Inc., Thousand Oaks, United States, pp 364-372 https://doi.org/10.4135/9781452218601.n39

Toomey AH, Knight AT, Barlow J (2016) Navigating the space between research and implementation in conservation: research-implementation spaces. Conserv Lett 10(5):619-625. https://doi.org/10.1111/conl.12315

Tyler C (2017) Wanted: academics wise to the needs of government. Nature 552 (7683):7-7. https://doi.org/10.1038/d41586-017-07744-1

van den Hove S (2007) A rationale for science-policy interfaces. Futures 39(7). Pergamon. pp. 807-826. https://doi.org/10.1016/J.FUTURES.2006.12.004

van Kerkhoff L, Lebel L (2006) Linking knowledge and action for sustainable development. Annu Rev Environ Resour 31(1):445-477. https://doi.org/ 10.1146/annurev.energy.31.102405.170850

Vilkins S, Grant WJ (2017) Types of evidence cited in Australian Government publications. Scientometrics 113(3):1681-1695. https://doi.org/10.1007/ s11192-017-2544-2

Weible CM, Heikkila T, DeLeon P et al. (2012) Understanding and influencing the policy process. Policy Sci 45(1):1-21. https://doi.org/10.1007/s11077-0119143-5

Weiss CH (1979) The many meanings of research utilization. Public Adm Rev 39 (5):426. https://doi.org/10.2307/3109916

Wittemyer G, Berger J, Crooks KR et al. (2018) To advocate or not is no longer the question: paths to enhance scientific engagement. Bioscience 68(1):13-14. https://doi.org/10.1093/biosci/bix134

Wright M, Lin A, O'Connell M (2016) Humility, inquisitiveness, and openness: key attributes for meaningful engagement with Nyoongar people. Adv Ment Health 14(2):82-95. https://doi.org/10.1080/18387357.2016.1173516

\section{Data availability}

The datasets generated during and/or analysed during the current study are available in the Open Science Framework repository: https://osf.io/hfwqr/

\section{Acknowledgements}

We wish to thank the following people who contributed thoughts and ideas which helped to shape this manuscript: Karen Hussey, Brian Head, Kate Auty, Paul Grimes and Amelia Wegner. Barry Traill and April Reside provided helpful feedback on an earlier version of the manuscript. The Network of Environmental Social Scientists supported the forum which inspired the writing of this piece. We also thank Melanie Ryan, Carina Wyborn and many others who contributed to the public list of science policy opportunities. This research was supported by the Australian Government's National Environmental Science Program through the Threatened Species Recovery Hub, and the Centre for Marine Socioecology.

\section{Additional information}

Competing interests: The authors declare no competing interests.

Reprints and permission information is available online at http://www.nature.com/ reprints

Publisher's note: Springer Nature remains neutral with regard to jurisdictional claims in published maps and institutional affiliations.

\section{(c) (i)}

Open Access This article is licensed under a Creative Commons Attribution 4.0 International License, which permits use, sharing, adaptation, distribution and reproduction in any medium or format, as long as you give appropriate credit to the original author(s) and the source, provide a link to the Creative Commons license, and indicate if changes were made. The images or other third party material in this article are included in the article's Creative Commons license, unless indicated otherwise in a credit line to the material. If material is not included in the article's Creative Commons license and your intended use is not permitted by statutory regulation or exceeds the permitted use, you will need to obtain permission directly from the copyright holder. To view a copy of this license, visit http://creativecommons.org/ licenses/by/4.0/.

(c) The Author(s) 2018 